\title{
LA VIDEO-FILMACIÓN COMO TÉCNICA DE ESTUDIO DE MAMÍFEROS SILVESTRES: UN EJEMPLO DE JAGUARES EN EL NORESTE DE LA PENÍNSULA DE YUCATÁN
}

\author{
JUAN CARLOS FALLER-MENÉNDEZ ${ }^{1}$, LUIS A. LAGO-TORRES ${ }^{2}$, ALFONSINA \\ HERNÁNDEZ-CARDONA ${ }^{3}$, MEDERIC CALLEJA-ALVARADO,${ }^{4}$ GERARDO \\ CEBALLOS $^{5}$, CUAUHTÉMOC CHÁVEZ ${ }^{5}$ Y STACEY JOHNSON ${ }^{6}$
}

\author{
${ }^{1}$ Pronatura Península de Yucatán, A.C.; \\ Calle 32 \#269, entre 47 y 47-A, Col. Pinzón II \\ Mérida, Yucatán, México, CP. 97207 \\ ${ }^{2}$ Grupo DIC, S.A. de C.V. \\ Xocotitla 17-15, Col Xoco. \\ México, D.F., CP. 03330 \\ ${ }^{3}$ Facultad de Ciencias, UNAM; \\ Av. Universidad 3000 \\ Circuito Exterior S/N, Ciudad Universitaria, UNAM \\ México, D.F. CP. 04510 \\ ${ }^{4}$ Instituto Tecnológico de Conkal \\ Km. 16.3 Antigua Carretera Mérida-Motul \\ Conkal, Yucatán. CP. 97345 \\ ${ }^{5}$ Instituto de Ecología de la UNAM; \\ Circuito exterior s/n anexo al Jardín Botánico Exterior \\ Ciudad Universitaria, UNAM \\ México, D.F. CP. 04510 \\ Apartado Postal 70-275 \\ ${ }^{6}$ Lehigh Valley Zoo \\ PO Box 519 \\ 5150 Game Preserve Road \\ Schnecksville, PA 18078
}

\begin{abstract}
Resumen: En noviembre de 2006 se utilizó un prototipo de cámara de video, en la reserva privada El Zapotal, en la porción noreste de la Península de Yucatán, y obtuvimos la filmación de una pareja de jaguares en actitud de apareamiento. Esta filmación representa una de las primeras experiencias de su tipo, y ha proporcionado información única sobre comportamiento y fecha de apareamiento de jaguares libres, que es consistente con algunos resultados de investigaciones de amplio espectro y largo plazo sobre poblaciones de esta especie en Sudamérica.
\end{abstract}


Palabras clave: Apareamiento, Panthera onca, videofilmación, Yucatán

\begin{abstract}
In november 2006, using a prototype of video camera, we obtained the shooting of a pair of jaguars in mating attitude. This was done in the El Zapotal private reserve, in the northeastern portion of the Yucatan Peninsula, and represents one of the first experiences of its type, also providing unique information about the mating behavior and the date of occurrence. The latter is consistent with some results derived from wide spectrum, long term studies about jaguar populations in South America.
\end{abstract}

Key words: Mating, Panthera onca, videoshooting, Yucatan

\title{
INTRODUCCIÓN
}

Durante las últimas dos décadas se han generado estudios sistemáticos sobre aspectos de hábitos alimentarios, uso de hábitat y áreas de actividad del jaguar. En México la mayor parte del conocimiento sobre este felino es anecdótica y esporádica, habiendo poca información sobre su biología y ecología (Ceballos et al., 2006). Es por ello que cualquier dato sólido sobre estos temas es particularmente valioso.

La información disponible sobre hábitos y estacionalidad reproductivos de los jaguares libres, está basada en evidencia indirecta o circunstancial, como es el análisis de patrones de movimiento de hembras y machos con collares de posicionamiento, o la detección de pariciones, la observación de crías, el cálculo de la edad de éstas y la inferencia de cuándo nacieron (ej: Quigley y Crawshaw, 2002 y Scognamillo et al., 2002).

En la literatura los reportes sobre la reproducción de los jaguares libres indican que éstos en general lo hacen durante todo el año (Law, 2003). En algunas regiones como en El Pantanal (Brasil) hay evidencia que sugiere que los jaguares se aparean de tal manera que los nacimientos de sus crías ocurren en el periodo de mayor disponibilidad de presas, habiendo así mayor probabilidad de supervivencia para las crías (Quigley y Crawshaw, 2002).

Para el caso de México, una de las escasas referencias sobre la estacionalidad reproductiva la ofrece S. A. Leopold, quien citando un trabajo de G.F. Gaumer (1917), dice que el periodo de apareamiento de los jaguares en Yucatán ocurre en agosto y septiembre (Leopold, 2000), por lo que las crías nacerían entre noviembre y enero.

Las cámaras de video para documentar eventos reproductivos de fauna silvestre han sido utilizadas para varios grupos taxonómicos durante los últimos 50 años (Reif y Tornberg, 2006) particularmente las aves (ej. Hudson y Bird, 2006). La mayoría de los estudios registran los sucesos en los nidos y el tiempo en las entradas y salidas de los padres para la alimentación, cuidado de los polluelos etc (Hudson y Bird, 2006). Sin embargo, el uso de esta técnica en mamíferos es todavía incipiente, y ha servido para estudiar conductas de forrajeo, lugares de paso y de escape a la 
depredación (ej. Clevenger y Wierzchoeski, 2001 y Coss et al., 2005). Es por lo anterior que en el presente trabajo documentamos la filmación de parte de la conducta reproductiva de jaguares en vida libre en el Noreste de Yucatán.

\section{ÁREADEESTUDIO}

La reserva privada El Zapotal, con una extensión de 2,358 hectáreas, está ubicada en el municipio de Tizimín, Estado de Yucatán. Sus coordenadas son: $21^{\circ} 20^{\prime} 25^{\prime \prime}$ latitud Norte y $87^{\circ} 36^{\prime} 20^{\prime \prime}$ longitud Oeste (PPY 2004ㄹ, Figura 1), colindando con la porción sureste de la Reserva de la Biosfera de Ría Lagartos (RBRL), la cual tiene una superficie de 60,347 hectáreas (INE, 1999). El Zapotal fue adquirido en 2002 por la asociación civil Pronatura Península de Yucatán con fines de conservación. Antes de ello, la actividad predominante en el predio era la ganadería extensiva.

Esta reserva, situada 11 kilómetros al sur de la línea costera, pertenece a la zona ecológica tropical subhúmeda (Challenger, 1998), y aproximadamente a 10 kilómetros al oriente la clasificación cambia a tropical húmeda. La reserva se ubica en el centro de una estrecha zona de transición rápida en cuanto a precipitación pluvial. Por ejemplo, en una distancia de 15 kilómetros, el promedio anual varía de $700 \mathrm{~mm}$ al norte hasta los 1,100 mm al sur (PPY 2004). En la zona de El Cuyo (en la costa, a $15 \mathrm{~km}$ al Noroeste de El Zapotal) los meses más fríos son enero y febrero, con una media de $24.6^{\circ} \mathrm{C}$, y los meses más calientes son junio y agosto, con $27.6^{\circ}$. El mes más seco es abril y el más lluvioso septiembre (INE, 1999), siendo la temporada de lluvias entre junio y octubre.

La topografía de la región se caracteriza por relieves planos o casi planos, con ligeras pendientes que permiten considerarla uniforme (INE, 1999). Una característica

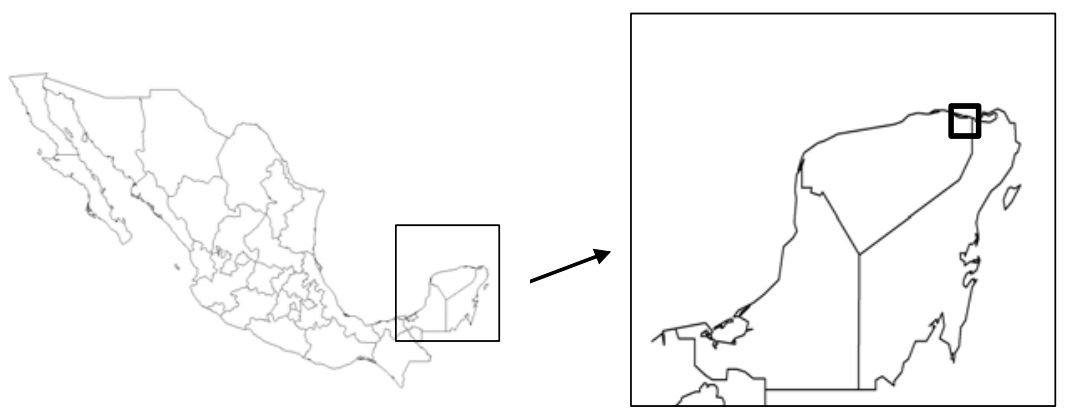

Figura 1. Ubicación de la zona de estudio, en el extremo noreste del Estado de Yucatán, México. 
importante de la región es la gran cantidad de cuerpos de agua dulce permanentes (cenotes) y temporales (aguadas), asociados a líneas de debilidad tectónica muy abundantes en la zona (García-Gil, 2004).

En cuanto a la vegetación, la mayor parte de la superficie (alrededor del 70\%) está cubierta por selva mediana subperennifolia de 15 o más años de antigüedad, aunque menos del $5 \%$ corresponde a selva totalmente desarrollada. Aproximadamente $20 \%$ de la superficie está cubierta por vegetación secundaria de menos de 5 años de edad, y 9\% está cubierta, en iguales proporciones, por selva baja inundable, tasistales y pastizales inundables (González-Iturbe y Tun, 2004).

La zona donde se encuentra inmerso El Zapotal forma parte de un sistema de humedales que incluye tres reservas costeras: Reserva Estatal Bocas de Dzilam (REBD) y RBRL (ambas en Yucatán), y el Área de Protección de Flora y Fauna Yum Balam (APFFYB, en Quintana Roo), que en conjunto abarcan más de 200 kilómetros de litoral y contienen aproximadamente 140,000 hectáreas de selvas y humedales. Aquí se ha identificado una población importante de jaguares, y en tres años de estudio con cámaras automáticas (2004-2006), se detectó dentro de El Zapotal un total de cinco individuos de jaguar (tres en 2004 y dos nuevos en 2006), todos machos, y una densidad de entre 1.5 y 5 individuos por cada 100 km2 (Faller et al., en preparación).

\section{MÉTODO}

Dada la alta incidencia de jaguares dentro de El Zapotal, se decidió instalar un prototipo de cámara de video automática para la filmación de individuos de esta especie. El sistema de filmación fue desarrollado por Grupo DIC, S.A. de C.V., con los siguientes elementos (Figura 2):

1) Minicámara alámbrica de video para circuito cerrado de televisión, con tecnología CMOS de color con lente de 3.6 mm, 12 LEDs infrarrojos para iluminación nocturna, con un alcance de $6 \mathrm{~m}$ (en modo nocturno, la imagen es en blanco y negro), y un sensor de intensidad lumínica para encender o apagar la iluminación infrarroja. Entrega una señal en banda base 1 Vpp (RCA). Su resolución horizontal es de 380 líneas. Su temperatura de operación esta entre los $-10^{\circ} \mathrm{C}$ y los $50^{\circ} \mathrm{C}$. Su sensibilidad a la luz, sin LEDs, es de 1 lux, y con LEDs es de 0 lux.

2) Sistema de grabación de video digital (Digital Video Recorder, DVR) de estado sólido miniatura. Tanto el vídeo, como la configuración del sistema, se almacenan en una tarjeta de memoria. Con un solo canal de entrada de video, incluye un sistema de detección de movimiento virtual (Apéndice).

Este sistema fue instalado el 18 de noviembre de 2006 sobre un camino interno de la reserva (coordenadas: $21^{\circ} 21^{\prime} 39.5^{\prime \prime}$ latitud norte, $87^{\circ} 36^{\prime} 59.2^{\prime \prime}$ longitud 


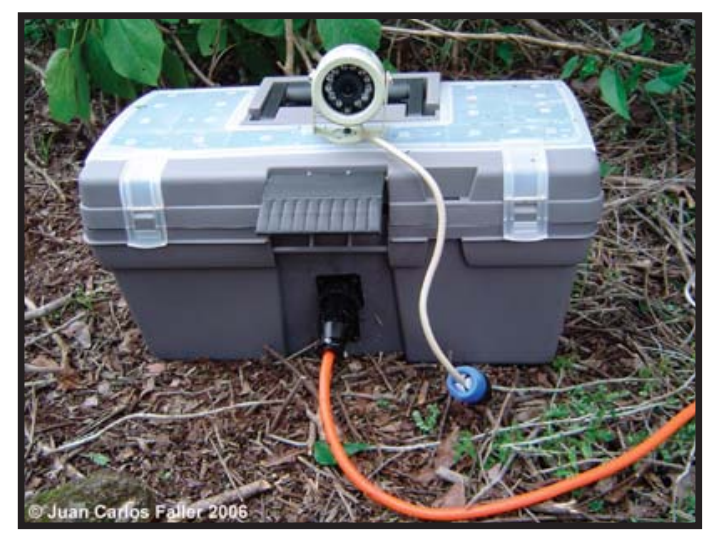

Figura 2. Prototipo de video-cámara usado para la filmación de jaguares en el norte de Yucatán.

oeste), menos de 50 metros hacia el oriente de donde entre mayo y julio una estación de fototrampeo obtuvo varias imágenes de tres jaguares machos distintos.

Para aumentar las probabilidades de filmación, frente a la cámara de video pusimos un cebo olfativo, consistente en una excreta fresca de jaguar macho en cautiverio (obtenida bajo la supervisión del MVZ. Fernando Victoria, del Zoológico Centenario de Mérida).

Al día siguiente de la instalación, regresamos para revisar el equipo y hacer los últimos ajustes, terminando el proceso a las 12:00 hrs del 19 de Noviembre.

\section{RESULTADOS}

Menos de 16 horas después de ser instalada la video cámara, entre las 03:53 hrs y las 04:00 hrs. del 20 de noviembre, se obtuvo una videofilmación con una duración total de 60 segundos, dividida en 8 segmentos de entre 4 y 22 segundos cada uno, cuya descripción es la siguiente:

1) 03:53:08 - 03:53:30 hrs.: aparece un jaguar macho se acerca y asoma a la cámara, volteando y oliendo el cebo olfativo, y saliendo hacia la derecha del campo de visión. (Figura 3).

2) 03:54:15 - 03:54:19 hrs.: un jaguar hembra aparece de frente en el campo de visión de la cámara, en actitud sumisa y/o precavida, orillándose hacia la izquierda del camino y mirando hacia la derecha frente a la cámara. (Figura 4). 

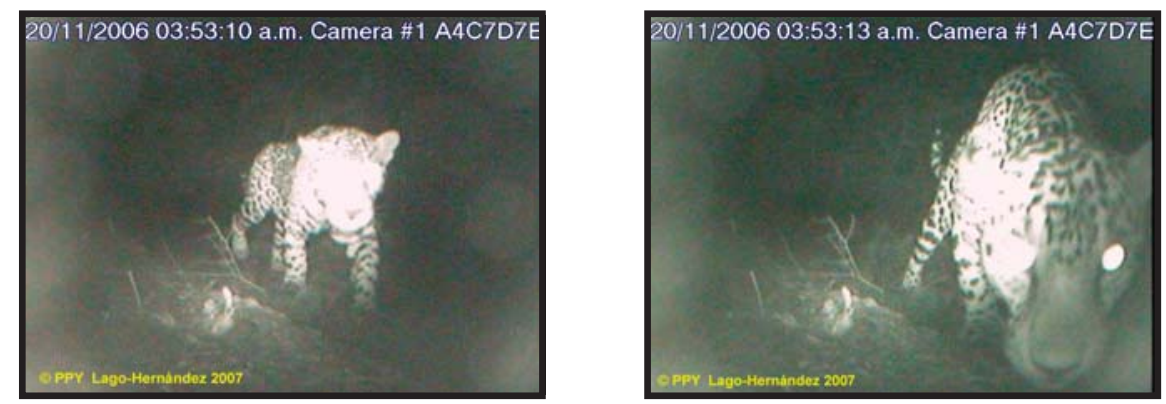

3) 03:54:22 - 03:54:26 hrs.: Aparece el jaguar macho desde la derecha del campo de visión, y la hembra se muestra sumisa, agazapándose y mirando al macho; éste se aproxima con seguridad hasta quedar en escuadra sobre la hembra agazapada. La actitud de la pareja puede describirse como pre-copulatoria. (Figura 5).

4) 03:56:44 - 03:56:48 hrs.: El jaguar macho camina hacia la cámara, y al llegar al punto donde se encuentra el cebo olfativo sale del campo de visión hacia la derecha.

5) 03:57:06 - 03:57:11 hrs.: El jaguar hembra sigue los mismos pasos del jaguar macho.

6) 03:57:16 - 03:57:29 hrs.: El jaguar macho entra desde la derecha al campo de visión y camina alejándose de la cámara, se detiene en el centro del campo de visión y voltea hacia atrás por su lado derecho, se da la vuelta y regresa por donde vino.

7) 03:57:52 - 03:57:56 hrs.: El jaguar macho entra desde la derecha al campo de visión y camina alejándose de la cámara, sin voltear.

8) 03:59:56 - 04:00:00 hrs.: El jaguar hembra sigue los mismos pasos del macho.

El jaguar macho en esta videofilmación (llamado "Jaguar Y") resultó ser el individuo más fotografiado con cámaras-trampa dentro de El Zapotal entre marzo y julio de 2006 (Figura 6), siendo un nuevo registro para el estudio. Por su parte, el jaguar hembra es
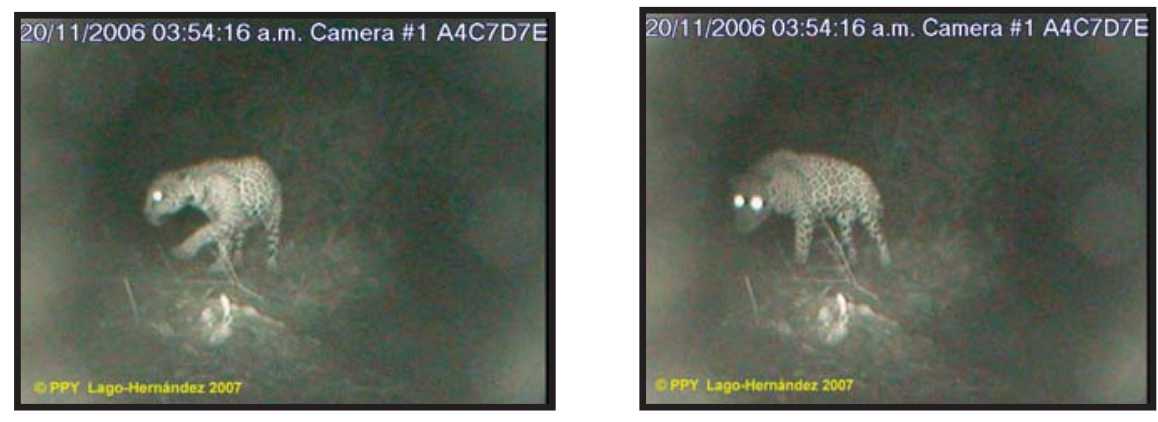

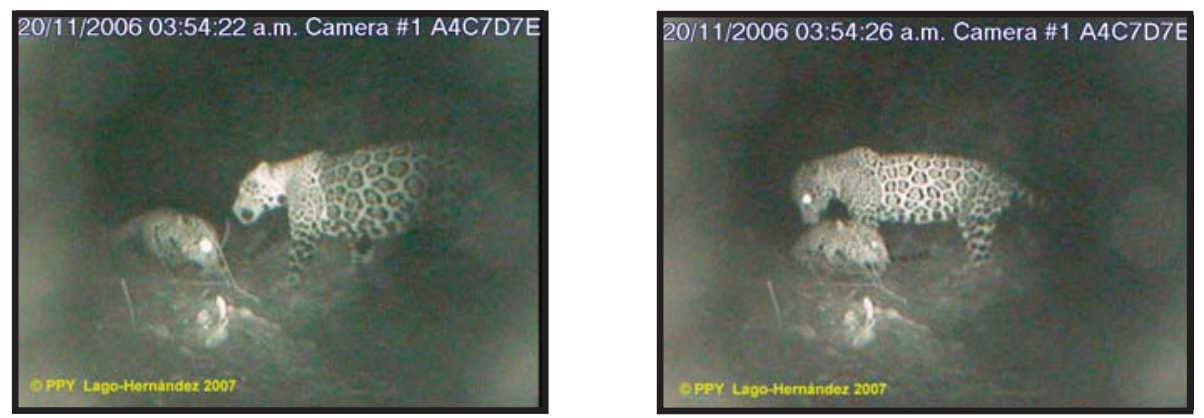

un nuevo registro para nuestro estudio, siendo éstas las primeras imágenes que se obtienen de ella. Adicionalmente, es apenas el segundo registro confirmado de una hembra de jaguar en tres años dentro de los 200 km² del área de estudio con cámarastrampa (Faller et al., en preparación).

\section{DISCUSIÓN}

En la filmación, el jaguar hembra sigue constantemente, a poca distancia, los pasos del jaguar macho, lo que, aunado al comportamiento de ambos individuos observado en el tercer segmento de la grabación, nos permite inferir que estos individuos se encuentran en una fase de apareamiento.

En caso de resultar preñada la hembra, dado el periodo de gestación promedio de 100 días, y tomando en cuenta una duración del celo de entre 6 y 17 días (Law, 2003), las crías nacerían a principios del mes de marzo, en los últimos días del invierno, en medio de la temporada de secas en la región. Esto es consistente con lo inferido para los jaguares de El Pantanal brasileño (Quigley y Crawshaw, 2002), ya que:
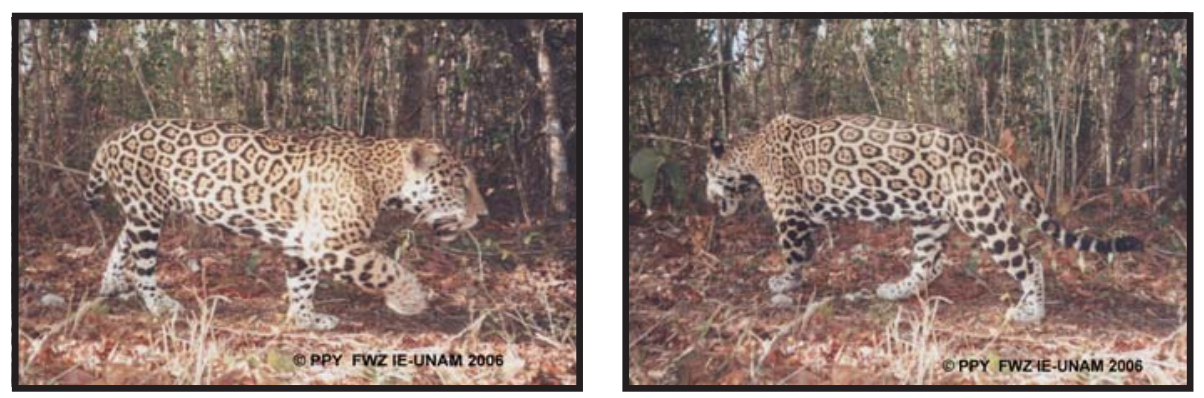
1) La temporada de secas es la mejor etapa del año para los jaguares en términos de cacería en la región de El Zapotal, ya que la presencia de presas alrededor de los abundantes cuerpos de agua es predecible y constante.

2) En esta temporada es escaso el número de mosquitos, tábanos y otros insectos picadores que podrían dañar a las crías.

\section{AGRADECIMIENTOS}

Agradecemos al Biol. Jesús Pacheco Rodríguez por sus comentarios y aportación al articulo.

\section{LITERATURACITADA}

Ceballos, G., C. Chávez, R. List, R. Medellín, C. Manterola, A. Rojo, M. Váldez, D. M. Brousset, S. M. B. Alcántara (Comité editorial) 2006. Proyecto para la conservación y Manejo del Jaguar en México. Serie proyectos de Recuperación de Especies Prioritarias. Número 14. SEMARNAT, México D.F. 12:13.

Challenger, A. 1998. Utilización y conservación de los ecosistemas terrestres de México. Pasado, presente y futuro. Conabio, IB-UNAM, Sierra Madre. 381 y 391.

Clevenger, A.P. y J. Wierzchowski. 2001. Gis-based modeling approaches to identify mitigation placement along roads. en http://www.icoet.net/downloads/GIS.pdf

Coss, R.G., Ramakrishnan, U. y Schank, J. 2005. Recognition of partially concealed leopards by wild bonnet macaques (Macaca radiata). The role of the spotted coat. Behav. Process,68:145-163.

Faller-Menéndez, J.C., C. Chávez-Tovar, S. Johnson, y G. Ceballos-González. Jaguares en el Noreste de la Península de Yucatán: sobreviviendo a través de milenios de impacto humano. En preparación.

Hudson M-A y D.M. Bird 2006 An Affordable Computerized Camera Technique for Monitoring Bird Nests. Wildlife Society Bulletin, 34 (5):1455

García Gil, G. 2004. Reconocimiento Geomorfológico y Geohidrológico de la Meso Región El Zapotal, Yucatán, México. Informe final de trabajo presentado a Pronatura Península de Yucatán. P. 10.

González-Iturbe, J. y F. Tun. 2004. Vegetación y Flora del Rancho 'El Zapotal', Municipio de Tizimín, Yucatán: Informe Técnico Final para Pronatura Península de Yucatán. P. 1.

Instituto Nacional de Ecología (INE 1999). Programa de manejo Reserva de la Biosfera Ría Lagartos. Semarnap. Pp. 7, 16, 19.

Law, C. (ed.). 2003. Guidelines for Captive Management of Jaguars. http://www.jaguarssp.org/ Animal\%20Management.htm. P. 29.

Leopold, A.S. 2000. Fauna Silvestre de México. Reimpresión. Editorial Pax. México. P. 531

Pronatura Península de Yucatán, A.C. (PPY 2004a). Plan de Manejo. Reserva Privada El Zapotal. Borrador interno. Junio de 2004. P. 4. 
Pronatura Península de Yucatán, A.C. (PPY 2004b). Sistema de Información Geográfica. El Zapotal, Yucatán, México. Julio de 2004.

Quigley, H.B. y P.G. Crawshaw. 2002. Reproducción, crecimiento y dispersión del jaguar en la región de El Pantanal de Brasil. Pp. 292: 293 y 299, en: Jaguares en el nuevo milenio: Una evaluación de su estado, detección de prioridades y recomendaciones para la conservación de los jaguares en América (Medellín, R.A., C. Chetkiewicz, A. Rabinowitz, K.H. Redford, J.G. Robinson, E. Sanderson, y A. Taber, eds.). Fondo de Cultura Económica, Universidad Nacional Autónoma de México/Wildlife Conservation Society. México D. F.

Reif, V. y R. Tornberg. 2006.Using time-lapse digital video recording for a nesting study of birds of prey. European Journal of Wildlife Research, 52: 251-258

Scognamillo, D., I.E. Maxit, M. Sunquist y L. Farrell. 2002. Ecología del jaguar y el problema de la depredación de ganado en un hato de los llanos venezolanos. Pp. 142 y 146, en: Jaguares en el nuevo milenio: Una evaluación de su estado, detección de prioridades y recomendaciones para la conservación de los jaguares en América. (Medellín, R.A., C. Chetkiewicz, A. Rabinowitz, K.H. Redford, J.G. Robinson, E. Sanderson, y A. Taber, eds.). Fondo de Cultura Económica, Universidad Nacional Autónoma de México/Wildlife Conservation Society. México D.F. 


\begin{abstract}
APÉNDICE
Funcionamiento y operación del sistema de detección virtual:

Las secciones del campo de visión que se desee sean sensibles al movimiento, son seleccionadas sobre una imagen, tomada con la misma cámara de video, del sitio a monitorear (Figura A).

Hecho lo anterior, la cámara de video trasmitirá, durante su funcionamiento, las imágenes ("frames") al DVR (Digital Video Recorder), y éste comparará el video recibido con la imagen-muestra que contiene las secciones sensibles al movimiento; cuando detecte movimiento en las áreas definidas, se iniciará la grabación del video.

La duración de la grabación está dada por un parámetro que define el número de cuadros a grabar después de iniciada la operación (en nuestro caso, 20 cuadros, con un lapso de 0.1 seg entre cada cuadro). Si después de grabar el número de cuadros determinado se detecta movimiento, se inicia de nuevo el proceso de grabación, hasta que la unidad de memoria se llene o se retire del DVR.

Para descargar la información, se retira la unidad de memoria del equipo de grabación y se inserta a una computadora con el programa de cómputo "MemoCam iP", versión 5.40, diseñado por VideoDomain Technologies Ltd., se recuperan las imágenes grabadas.
\end{abstract}

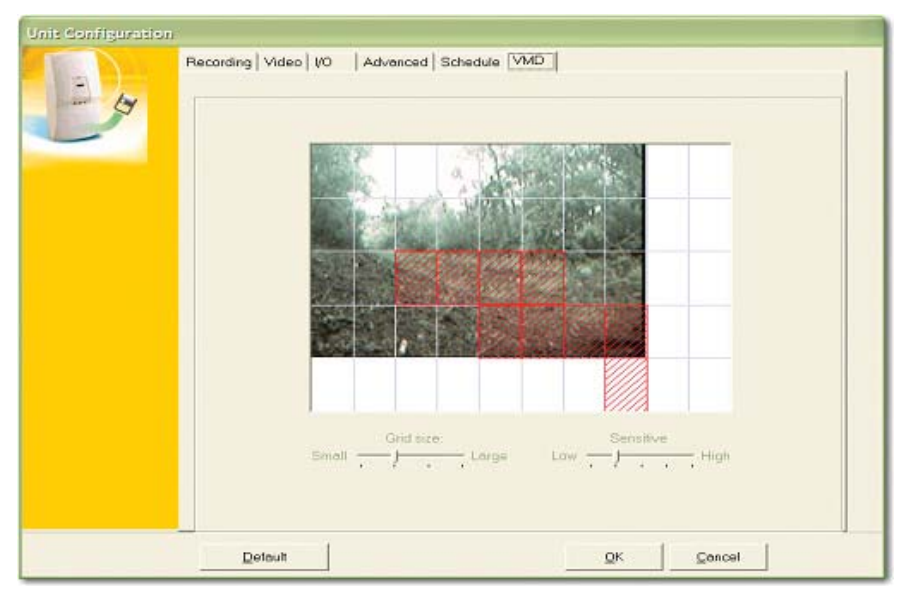

Figura A. Los recuadros rojos de la imagen anterior son las áreas sensibles a la detección de movimiento que fueron seleccionadas para esta videofilmación. 